\title{
SURFACES OF ELECTRON-EMITTING GLASSES STUDIED BY A SLOW POSITRON BEAM
}

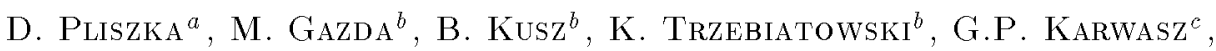 \\ W. Deng ${ }^{c}$, R.S. Brusa ${ }^{c}$ AND A. ZeCCA ${ }^{c}$ \\ ${ }^{a}$ Institute of Physics, Pedagogical University \\ Arciszewskiego 22B, 76-200 Słupsk, Poland \\ ${ }^{b}$ Faculty of Technical Physics and Applied Mathematics, Technical University \\ Narutowicza 11/12, 80-952 Gdańsk, Poland \\ 'Istituto Nazionale per la Fisica della Materia, Unita' di Trento, 38-050 Povo, Italy
}

\begin{abstract}
Semi-conducting glasses used for electron multipliers and microchannel plate devices are obtained by surface modification of $\mathrm{Pb}$ or Bi-reach silicon-based glasses. The reduced layer extends down to $200-500 \mathrm{~nm}$, much more than the effective depth of the electron-emitting layer. By the use of slow-positron beam we monitor the structural changes undergoing in near-to-surface layers after isothermal annealing. The measurements suggest a possible correlation between secondary-electron emission coefficient and the Doppler-broadening $S$-parameter. On these samples there were also performed atomic force microscopy, secondary electron emission, differential scanning calorimetry, and electric conductivity measurements.
\end{abstract}

PACS numbers: 71.60.+z, 78.70.Bj

\section{Introduction}

Semiconducting glasses, modified on surface, usually silicate glasses containing lead, bismuth or antimony, are the most common material used in electron multiplier devices. The use of glasses, which remain isolators in bulk, simplifies and reduces dimensions of these devices. The heat treatment in hydrogen atmosphere breaks oxygen-metal ion bonds in the near-to-surface layers. As a result dispersed atoms ( $\mathrm{Pb}, \mathrm{Bi}$ or $\mathrm{Sb})$ appear in the surface layer of the glass.

Most commonly used are lead-based glasses in which the reduced, semi-conducting layer extends down to $5 \mu \mathrm{m}$. The layer enriched with hydrogen atoms extends to the $200-500 \mathrm{~nm}$ depth. On the other hand, only the very first layer, which is silica rich and extends down to $20-50 \mathrm{~nm}$ is active for secondary electron emission [1]. The glass surface after the treatment is black due to the dispersed $\mathrm{Pb}$ particles. However, the exact chemical composition and the morphologic structure of these layers is still not fully understood [1]. 
The secondary emission properties depend on the temperature, time and also the atmosphere composition in which the treatment is done [2]. The emission properties are also subject to aging, in particular if the detectors are used to reveal atoms and ions. It has been empirically ascertain that prolonged reduction times improve aging properties not changing much the initial emission yield but the reason for this behaviour is not known. The aim of the present paper is to check if surface modifications of the conducting glasses can be monitored by the depth-resolved positron annihilation spectroscopy (PAS). Glass samples have been characterized by measurements of electrical conductivity in bulk and on surface, by secondary electron-emission measurements, by calorimetry, and by atomic force microscopy.

\section{Preparation of the samples}

Two kinds of electron emitting glasses have been studied: the first one silica-bismuth glasses, with $30 \mathrm{Bi}_{2} \mathrm{O}_{3} \cdot 70 \mathrm{SiO}_{2}$ molar stoichiometry, the second one silica-lead glass $40 \mathrm{PbO} \cdot 60 \mathrm{SiO}_{2}$. Lead glasses have been obtained by direct melting of oxides, in two stages, the final one at $1250^{\circ} \mathrm{C}$.

The bismuth samples were melted from $\mathrm{SiO}_{2}$ and bismuth nitrate $4 \mathrm{BiNO}_{3}(\mathrm{OH})_{2} \cdot \mathrm{BiOH}$ (the use of $\mathrm{Bi}_{2} \mathrm{O}_{3}$ leads to crystallisation and phase separation during cooling). The ground components were accurate crumbled and preliminary heated at $750^{\circ} \mathrm{C}$ to obtain the cohesion of the grains and pre-forming of $\mathrm{Bi}-\mathrm{O}-\mathrm{Si}$ bounds. The obtained ceramal was milled once again and melted at $1250^{\circ} \mathrm{C}$ for about $1 \mathrm{~h}$. During melting an intensive out-gassing (nitrogen oxides, water vapour) was observed. Solidified glasses were then annealed for $3 \mathrm{~h}$ at $350^{\circ} \mathrm{C}$. $\mathrm{X}$-ray diffraction analysis did not reveal any crystalline phase in the obtained material.

For bismuth-glass samples the isothermal $\left(300^{\circ} \mathrm{C}\right)$ reduction was performed in hydrogen atmosphere for times up to 90 hours. Four lead-glass samples the reduction temperature was $400^{\circ} \mathrm{C}$ with times up to $55 \mathrm{~h}$.

\section{Sample material properties}

\subsection{Electrical conductivity}

The electrical conductivity of (non-reduced) $30 \mathrm{Bi}_{2} \mathrm{O}_{3} \cdot 70 \mathrm{SiO}_{2}$ glass in bulk has been measured between $500^{\circ} \mathrm{C}$ and $700^{\circ} \mathrm{C}$ : at $500^{\circ} \mathrm{C}$ it is in the $10^{-12}(\Omega \mathrm{m})^{-1}$ range. The dependence of the electric conductivity on temperature in semi-log scale vs. $1 / T$ (Arrhenius plot) shows a linear dependence. From the dependence $\sigma=\sigma_{0} \exp (-E / k T)$ one can obtained the activation energy for Bi-Si glass, $E=1.33 \mathrm{eV}$.

The surface electrical conductivity for reduced bismuth samples is shown in Fig. 1. We can distinguish three phases during samples reduction. During phase I the surface conductivity rises from $1 \times 10^{-12}$ to $1 \times 10^{-11}(\Omega)^{-1}$ just after the first $30 \mathrm{~min}$ and then remains almost constant up to $1.5 \mathrm{~h}$ of annealing time. These values are typical for the conductivity mechanism due to isolated defects. While 


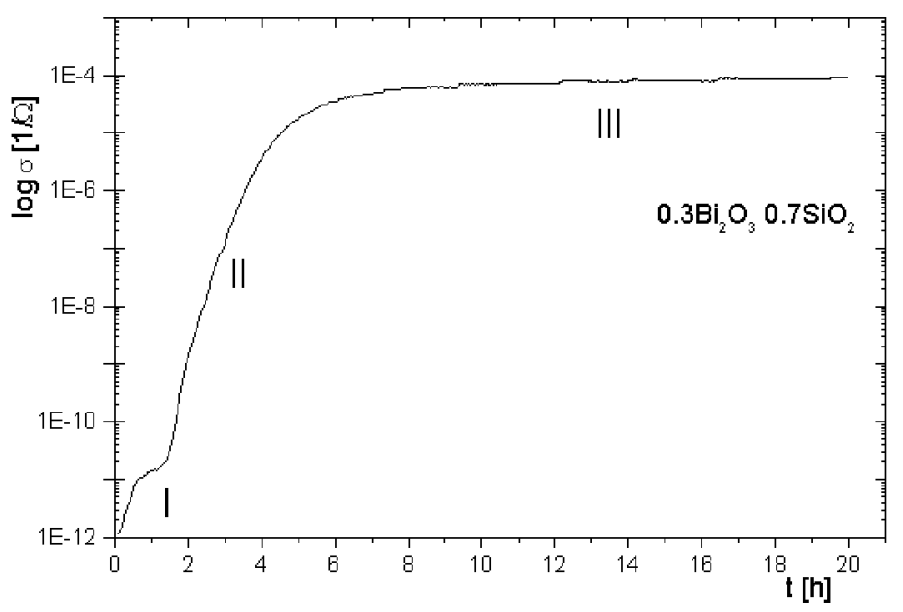

Fig. 1. Surface conductivity of reduced bismuth-glass samples vs. time of treatment $\left(300^{\circ} \mathrm{C}\right.$ reduction temperature).

continuing the reduction between 2 and 5 hours (phase II) the annealing of the surface conductivity rises by 5-6 orders of magnitude, indicating the formation of percolation paths. The further annealing above $6 \mathrm{~h}$ causes only a slight modification of the surface electric conductivity (phase III) caused by a slow growing of the reduced layer.

\subsection{Secondary emission coefficient}

The secondary emission coefficient has been measured by the dc method; for this reason no measurements for non-reduced samples were done. The results for bismuth samples are shown in Fig. 2. For all three samples the coefficient changes

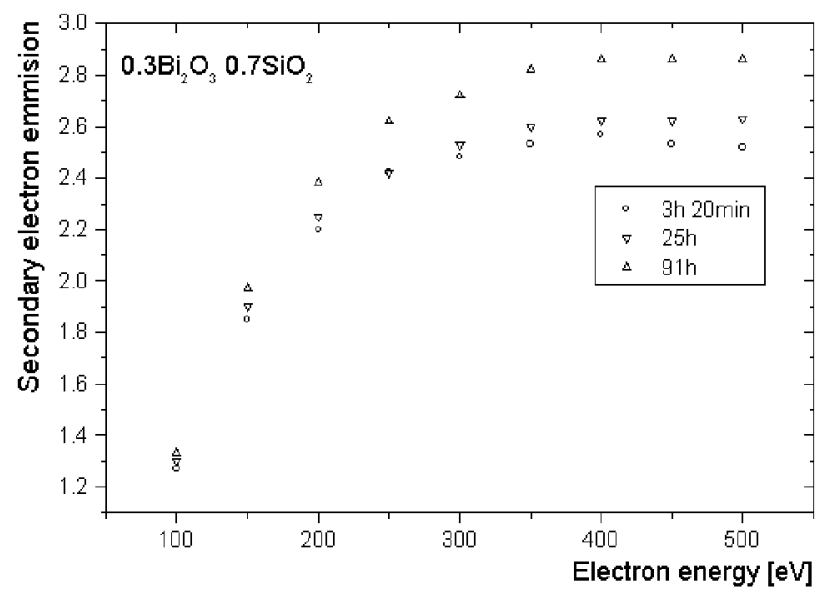

Fig. 2. Secondary emission coefficient of bismuth-glass samples. 
from 1.3 to 2.8 for the primary electron energy rising from 100 to $500 \mathrm{eV}$. For the sample reduced for $3 \mathrm{~h} 20 \mathrm{~min}$ a slight fall of the emission coefficient is observed at $400-500 \mathrm{eV}$. This could suggest a non-sufficient depth of the active layer obtained during reduction.

Generally, the secondary emission coefficient depends weakly on the reduction times: its maximum value changes from 2.5 after short ( $3 \mathrm{~h} 20 \mathrm{~min})$ treatment to 2.9 after prolonged reduction time. This maximum shifts gradually to higher incident energies, but also this dependence is weak.

\subsection{Differential scanning calorimetry}

The differential scanning calorimetry (DSC) has been performed for three bismuth-glass samples: as-obtained, reduced for $72 \mathrm{~h}$ at $300^{\circ} \mathrm{C}$ and reduced and then annealed under vacuum at $400^{\circ} \mathrm{C}$ for $5 \mathrm{~h}$, see Fig. 3 . The temperature range of measurements spans from $-100^{\circ} \mathrm{C}$ to $600^{\circ} \mathrm{C}$ with the heating speed of $10^{\circ} \mathrm{C} / \mathrm{min}$. The curve for the as-grown sample (A) shows only one maximum due to the one phase transition of the glass at $485^{\circ} \mathrm{C}$.

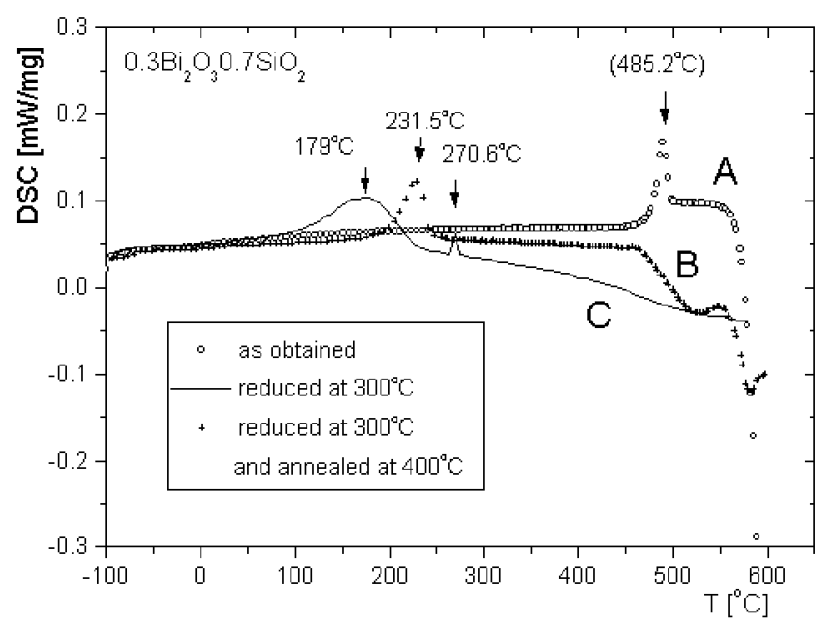

Fig. 3. Differential scanning calorimetry of Bi-Si glasses.

The curve for the reduced sample (B) shows a sharp peak at $270^{\circ} \mathrm{C}$. This peak can be related to the melting of surface droplets of bismuth. A large maximum extending from 100 to $200^{\circ} \mathrm{C}$ is probably due to the melting of $\mathrm{Bi}$ clusters of different dimensions inside the glass. A large width of this maximum is caused by dispersion of clusters diameters.

For the glass reduced and then annealed (sample C) there is no sharp peak at $270^{\circ} \mathrm{C}$. Probably, the surface Bi droplets evaporate during the heating, they diffuse inside the material or change their chemical composition. The large maximum observed at $180^{\circ} \mathrm{C}$ in the reduced samples now shifts to about $230^{\circ} \mathrm{C}$. This is caused by increasing number of larger clusters of $\mathrm{Bi}$ at the cost of smaller ones. 


\subsection{Atomic force microscopy}

Atomic force microscopy performed on the samples reduced at standard temperatures $\left(300^{\circ} \mathrm{C}\right.$ for $\mathrm{Bi}$ and $400^{\circ} \mathrm{C}$ for $\mathrm{Pb}$ glasses) does not show any difference with as-obtained samples. In order to evidence the difference, we performed an annealing at $580^{\circ} \mathrm{C}$. Such a procedure causes the granules to grow because the annealing temperatures exceed bismuth melting point. Indeed, as can be seen in Fig. 4, in the region between $100 \mathrm{~nm}$ and $1500 \mathrm{~nm}$ beneath the surface, large granules can be easily seen. No traces of such metallic granulates were observed on the surface of as-grown glass; in these samples the surface roughness (a few $\mathrm{nm}$ ) is caused by the process of polishing.

a)
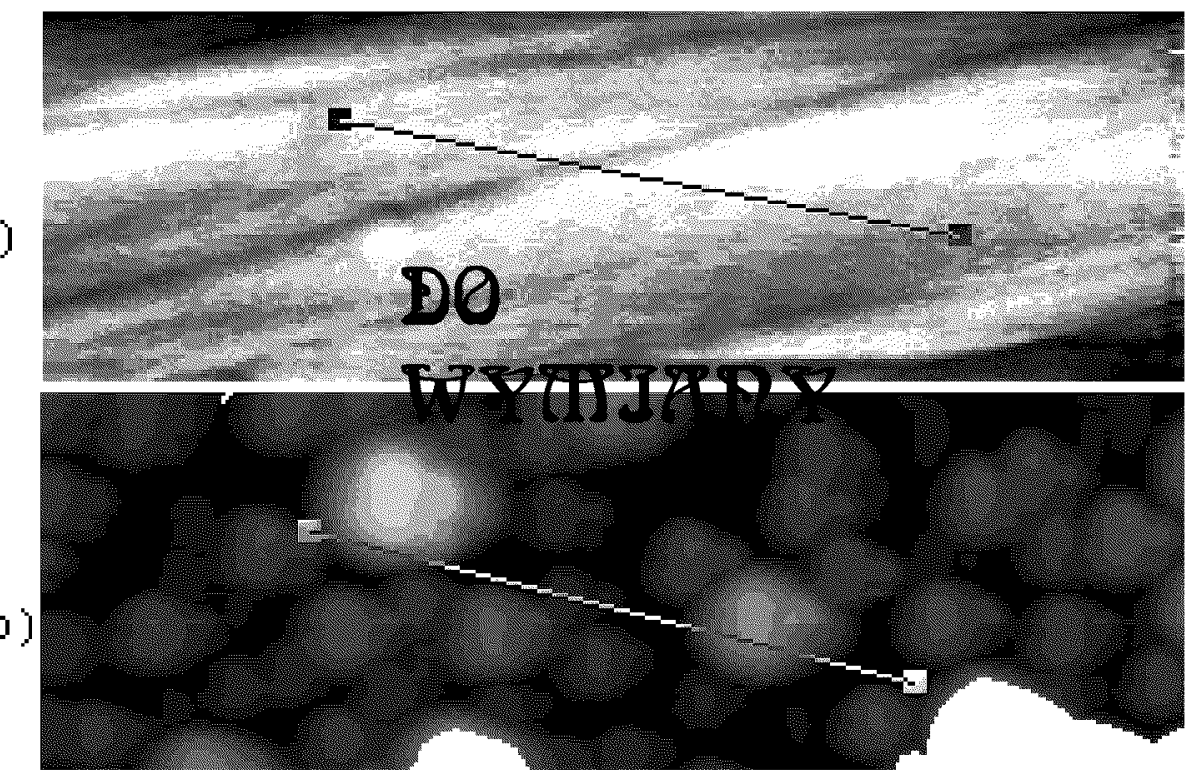

Fig. 4. AFM images of the $\mathrm{Bi}-\mathrm{Si}$ glass sample; (a) freshly broken sample, (b) the same part of the sample after annealing at $580^{\circ} \mathrm{C}$ for $21 \mathrm{~h}$.

\section{Positron spectroscopy}

\subsection{Experimental procedure}

Four Bi-glass (as-grown, reduced for $3 \mathrm{~h} 20 \mathrm{~min}, 25 \mathrm{~h}$ and $91 \mathrm{~h}$ ) and two Pb-glass (as-grown and reduced for $21 \mathrm{~h}$ ) samples were chosen for the present positron study.

Positron annihilation measurements were performed by the Doppler-broadening technique [3]. A high purity germanium detector of $26 \%$ efficiency was used to detect the annihilation radiation; the resolution of this detector at $511 \mathrm{keV}$ line was $1.2 \mathrm{keV}$. 
A slow positron beam with energy variable between $50 \mathrm{eV}$ and $25 \mathrm{keV}$ was obtained by moderating positrons from a $4 \mathrm{mCi}{ }^{22} \mathrm{NaCl}$ radioactive source in a $1 \mu \mathrm{m}$ thick single crystal tungsten foil. All beam handling has been obtained by electrostatic focussing. Details about the apparatus and the measurements are reported in Refs. [3, 4].

The shape of the $511 \mathrm{keV}$ annihilation line has been characterised by the $S$ parameter. The $S$ parameter was calculated as the ratio of the counts in the central area of the peak $\left(\left|511 \mathrm{keV}-E_{\gamma}\right| \leq 0.85 \mathrm{keV}\right)$ and the total area of the peak $\left(\left|511 \mathrm{keV}-E_{\gamma}\right| \leq 4.25 \mathrm{keV}\right)$. The $S$ parameter was measured as a function of the positron implantation energy in the $0.15-20 \mathrm{keV}$ energy range. The implantation depth (in $\AA$ ) has been obtained from the energy using the formula: $d=(400 / \rho) E^{1.4}$ with $E$ being the beam energy and $\rho$ - the glass density $\left(5.8 \mathrm{~g} / \mathrm{cm}^{3}\right.$ and $5.46 \mathrm{~g} / \mathrm{cm}^{3}$ for $\mathrm{Bi}$ and $\mathrm{Pb}$-glasses, respectively).

\subsection{Bulk properties}

The $S$-parameter measurements indicate a substantial difference between as-received and reduced glasses with little dependence on the chemical composition. Both the $\mathrm{Bi}$ and $\mathrm{Pb}$ non-reduced samples show a bulk $S$-parameter value of about 0.49 compared to a bulk value of $0.53-0.54$ for the reduced samples. The $S$-parameter value of 0.49 is close to the literature value for the non-defected $\mathrm{SiO}_{2}$ glass [5] if we allow for the above given values of the $S$-parameter window.

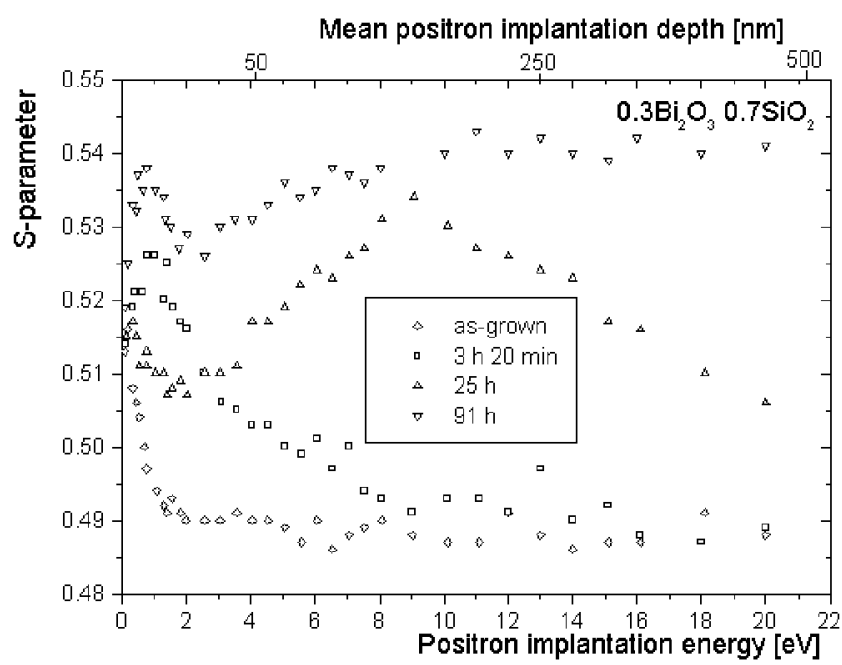

Fig. 5. Doppler broadening $S$-parameter for Bi-Si glasses.

The $S$-parameter at $500 \mathrm{~nm}$ depth starts to increase only after long reduction times (above $10 \mathrm{~h}$ ), see Fig. 5 . With a reduction time of $3 \mathrm{~h}$, only the first 20 -nm-layer shows an increase in the $S$-parameter. The rise from 0.49 to 0.53 should be attributed to the formation of metal clusters and/or precipitates and/or defects related to these agglomerates. The existence of metal clusters is indicated by other measurements in this paper. 


\subsection{Near-to-surface layers}

Also the surface properties of the $\mathrm{Bi}$ and $\mathrm{Pb}$ glasses show clear similarities. In non-reduced samples the $S$-parameter falls quickly in the first $30 \mathrm{~nm}$ of depth, see Fig. 6.

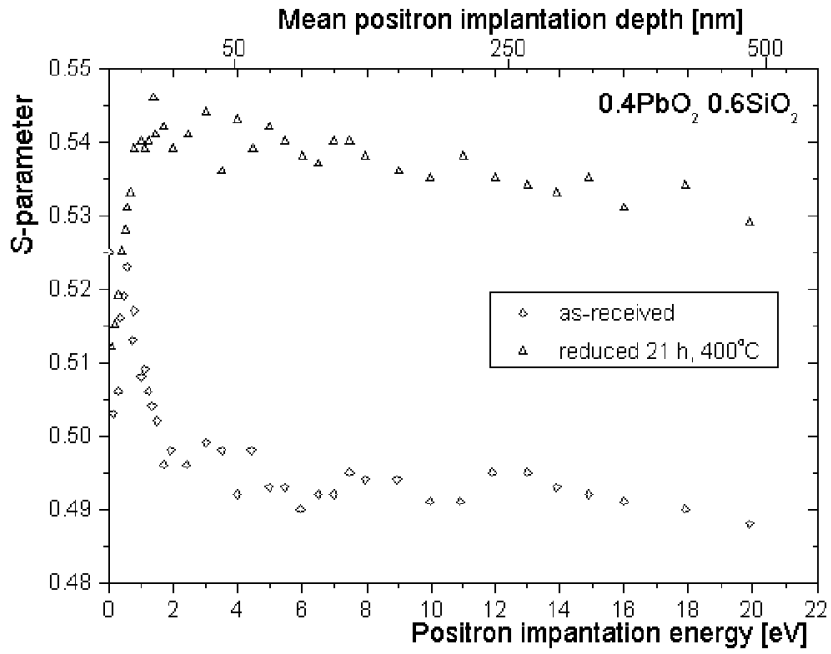

Fig. 6. Doppler broadening $S$-parameter dependence for $\mathrm{Pb}-\mathrm{Si}$ glasses.

In all reduced samples the $S$-parameter rises with the implantation range for the first 20-30 $\mathrm{nm}$ depth, independently on the chemical composition. This picture resembles the typical behaviour of the $S$-curves for metals, with surface positron-trapping states. Note that, even after the shortest ( $3 \mathrm{~h} 20 \mathrm{~min})$ treatment times, the samples show a surface conductivity already 6 orders of magnitude higher than the as-obtained glasses.

In the limit of zero implantation energy the $S$-parameter of all studied samples show the same (within the error bar) $S$-parameter of about 0.515 , independently on the reduction procedure. This could be related to the formation of positronium on the surface. We have also monitored the $V$-parameter (peak-to-valley) ratio characteristic of the $3-\gamma$ decay. The $V$-parameter falls quickly for implantation energies from $50 \mathrm{eV}$ to $1 \mathrm{keV}$, by a factor of two for $\mathrm{Bi}$-glasses and by a factor of four for Pb-glasses.

\subsection{Intermediate layers}

As far as the Bi sample reduced for $3 \mathrm{~h} 20 \mathrm{~min}$ and the $\mathrm{Pb}$ sample reduced for $21 \mathrm{~h}$ show a monotonic dependence of the $S$-parameter between $20 \mathrm{~nm}$ and the $500 \mathrm{~nm}$ depth, the Bi samples reduced for $25 \mathrm{~h}$ and $91 \mathrm{~h}$ show a minimum of the $S$-parameter at about $40 \mathrm{~nm}$ depth. The reason for such behaviuor is not clear. One can hypothesize a partial filling of the defect sites by hydrogen atoms in this region. However, in order to verify this hypothesis, additional measurements on samples degassed in vacuum are planned. 


\section{Acknowledgments}

This work was supported in part by the Committee for Scientific Research (Poland), grant no. 7 TO8D 02719 and INFM (Italy) post-doc grant (W.D.).

\section{References}

[1] A.M. Then, C.G. Pantano, J. Non-Cryst. Solids 120, 178 (1990).

[2] K. Trzebiatowski, A. Witkowska, M. Chybicki, Polish Ceramic Bulletin 19, 157 (1998).

[3] A. Zecca, M. Bettonte, J. Paridaens, G.P. Karwasz, R.S. Brusa, Meas. Sci. Technol. 9, 409 (1998).

[4] R.S. Brusa, G.P. Karwasz, N. Tiengo, A. Zecca, F. Corni, G. Otta viani, R. Tonini, Phys. Rev. B 61, 10154 (2000).

[5] P. Ashoka-Kumar, K.G. Lynn, D.O. Welch, J. Appl. Phys. 76, 4935 (1994). 